\title{
Thermodynamics of moisture sorption in tobacco (Nicotiana tabacum L.) seeds
}

\author{
Nesho Toshkov ${ }^{1}$, Lazar Lazarov², Venelina Popova ${ }^{2, *}$, Tanya Ivanova ${ }^{2}$, and Nikolay \\ Menkov ${ }^{1}$ \\ ${ }^{1}$ University of Food Technologies, Department of Processes Engineering, 4002 Plovdiv, Bulgaria \\ ${ }^{2}$ University of Food Technologies, Department of Tobacco, Sugar, Vegetable and Essential Oils, 4002 \\ Plovdiv, Bulgaria
}

\begin{abstract}
In this study, the thermodynamic characteristics of tobacco seeds were investigated, based on experimental data from equilibrium moisture isotherms at desorption. An empirical exponential relationship was found for the decrease of the net isosteric heat and the differential entropy, based on the Clausius-Clapeyron equation, in response to the increase in moisture content; the values of the two parameters varied from 31.09 to $1.46 \mathrm{~kJ}^{-\mathrm{mol}^{-}}$ ${ }^{1}$ and from 91.53 to $4.29 \mathrm{~J} \cdot \mathrm{mol}^{-1} \cdot \mathrm{K}^{-1}$, respectively. The linear relationship between the enthalpy and the entropy in the moisture desoption of tobacco seeds supported the validity of the enthalpy-entropy theory. The value of Gibbs free energy was positive and the harmonic temperature (297.5 K) was lower than the isosteric temperature $(339.6 \mathrm{~K})$. The outcomes from the study provide for the deeper insight into the process of moisture desorption of tobacco seeds.
\end{abstract}

\section{Introduction}

Desorption isotherms are an essential element of the analysis and control of different processes related to the preservation, drying, packaging, and blending of food products [1]. The thermodynamic properties of various biological objects, i.e. the heat of sorption and the differential entropy, can be characterized on the basis of sorption data analysis [2, 3]. These properties provide important evidence about the mechanism of water sorption and its bonding to the solid skeleton; they are also useful for energy valuation in accomplishing the process of drying of various food and agricultural products.

A number of studies have validated the applicability of the Clausius-Clapeyron equation for the determination of the heat of sorption of various objects based on the data derived from the integral interpretation of sorption isotherms at different temperature levels $[4,5]$. In turn, the enthalpy-entropy compensation theory (EECT) has been found highly relevant in the exploration of desorption reactions in various experimental matrices $[6,7,8]$.

Tobacco seeds (Nicotiana tabacum L.) can be regarded an underestimated plant biomass with potential for use in diverse value-added products; moreover, they are a waste from

\footnotetext{
*Corresponding author: vpopova2000@abv.bg
} 
tobacco leaf production available in large amounts in many countries [9-11]. Tobacco seeds are nicotine-free and rich in nutritive and bioactive compounds (vitamins, minerals, fiber, protein, glyceride oil, etc.), with a number of benefits in human and animal nutrition [12-14].

A critical moment in the collection and storage of tobacco seeds with food and feed functions is the compulsory prevention of detrimental processes, which are essentially related to the availability of water that is bound in the biological matrix. Therefore, all aspects of the hygroscopic properties of tobacco seeds are equally important in the overall assessment of seed quality, of proposed processing technologies or of seed use potential benefits.

According to a preceding study (own unpublished data) the modified Chung-Pfost model [15] was the best fitting for the description of the desorption isotherms of Oriental tobacco seeds. Therefore, current study applies the obtained modified model for the determination of the basic thermodynamic properties of tobacco seeds, the net isosteric heat of desorption and the differential entropy, with the vision of a deeper insight into the process of moisture desorption of tobacco seeds. The outcomes from the study provide new details about the hygroscopic behavior of tobacco seeds, which might be of practical importance in seed safe storage and usability design choices.

\section{Materials and methods}

\subsection{Plant material}

Authentic seeds of "Kroumovgrad 90" variety of the Oriental type tobacco (N. tabacum L.) were the primary raw material in the study. According to the objectives of this work, the seeds were producer-supplied and not intended for planting purposes [16].

\subsection{Desorption isotherms}

The basis for the determination of the thermodynamic properties of tobacco seeds in this study were their desorption isotherms, obtained at three temperatures, in particular $10^{\circ} \mathrm{C}$, $25^{\circ} \mathrm{C}$ and $40^{\circ} \mathrm{C}$, and water activities $\left(a_{w}\right)$ ranging from 0.113 to 0.823 . The modified ChungPfost model was defined as the most adequate for the description of the obtained desorption isotherms. The Chung-Pfost model, correlating the equilibrium moisture $(M)$ of tobacco seeds with water activity, was used in the following modified form:

$$
a_{w}=\exp \left[\frac{-251.0101}{t+13.995116} \exp (-0.306062 M)\right]
$$

\subsection{Thermodynamic properties}

\subsubsection{Net isosteric heat of desorption}

The total isosteric heat of desorption is the sum of the latent heat of evaporation of pure water and the heat of desorption. The latter can be obtained from the model describing the respective desorption isotherms at a series of temperatures and the Clausius-Clapeyron equation $[17,18]$ :

$$
\frac{d \ln \left(a_{w}\right)}{d(1 / T)}=\frac{Q_{s t, n}}{R}=\frac{q_{s t}-L_{v}}{R}
$$


where: $Q_{s t, n}$ is the net isosteric heat of desorption, $\mathrm{J} \cdot \mathrm{mol}^{-1} ; q_{s t}$ - the total isosteric heat of desorption, $\mathrm{J}_{\mathrm{mol}}{ }^{-1} ; R$ - the universal gas constant $\left(8.314 \mathrm{~J} \cdot \mathrm{mol}^{-1} \cdot \mathrm{K}^{-1}\right) ; L_{v}$ - the latent heat of vaporization of water, $\mathrm{J}_{\mathrm{mol}}^{-1} ; a_{w}$ - the water activity, and $T$ - the absolute temperature, $\mathrm{K}$.

The Clausius-Clapeyron equation is transformed in its linear form [19]:

$$
\ln \left(a_{w}\right)=-\left(\frac{Q_{s t, n}}{R}\right) \cdot \frac{1}{T}+\text { const }
$$

The equation provides the linear correlation between $\ln \left(a_{w}\right)$ and $(1 / T)$ at a constant equilibrium moisture content $\left(M_{e q}=\right.$ const $)$.

Then, by applying the Chung-Pfost model (eq. 1), the values of $a_{w}$ were calculated, corresponding to a moisture content varied from $5 \%$ to $15 \%$ by a step of $2 \%$ (on a dry weight basis, d.b.) at the three single temperatures $\left(10^{\circ} \mathrm{C}, 25^{\circ} \mathrm{C}\right.$ and $\left.40^{\circ} \mathrm{C}\right)$, respectively. $Q_{s t, n}$ values were obtained from the slope of the curve in the graphical dependency between $\ln \left(a_{w}\right)$ and $(1 / T)$.

\subsubsection{Differential entropy}

The differential entropy of desorption $(\Delta S)$ can be derived from the Gibbs-Helmholtz equation [20]:

$$
\Delta S=\frac{Q_{s t, n}-\Delta G}{T}
$$

where the Gibbs free energy $(\Delta G)$ is calculated as:

$$
\Delta G=-R T \ln \left(a_{w}\right)
$$

The interrelation between the shift in water sorption capacity and $\Delta G$ is paralleled by resultant variations in the enthalpy and the entropy. When equation (5) is substituted in equation (4), the following model is obtained:

$$
-\ln \left(a_{w}\right)=\frac{Q_{s t, n}}{R T}-\frac{\Delta S}{R}
$$

Then, $\Delta S$ values can be obtained from the intersection of the linearized experimental curve and the $a_{w}$ axis.

In order to describe the relationship between $Q_{s t, n}$ and the moisture content the following, empirically-derived, exponential correlation [21] can be used:

$$
Q_{s t, n}=q_{0} \exp \left(-\frac{M_{e q}}{M_{0}}\right)
$$

where: $M_{e q}$ is the equilibrium moisture content, \% d.b.; $M_{o}$ - the initial moisture content, $\%$ d.b.; $q_{o}$ - the net isosteric heat of desorption of the first molecular layer, J.mol ${ }^{-1}$.

\subsubsection{Enthalpy-entropy compensation theory (EECT)}

According to the postulates of the EECT, the relationship between the enthalpy and the entropy of the desorption process in many food products is linear $[3,5,6]$ :

$$
Q_{s t, n}=T_{\beta} \Delta S+\Delta G_{\beta}
$$

where: $T_{\beta}$ is the isokinetic temperature and $\Delta G_{\beta}$ is the free energy at that temperature.

In this equation, $T_{\beta}$ is a highly informative indicator, suggestive of the temperature state at which all interactions within the solid body progress at equal rate [4]. The mathematical 
sign of $\Delta G_{\beta}$ value (negative or positive), respectively, shows if the process of desorption is a spontaneous or a non-spontaneous one.

Therefore, $T_{\beta}$ and $G_{\beta}$ were computed by equation (8), providing the dependency of $Q_{s t, n}$ on $\Delta S$. Then a test for the existence of true compensation was applied, as recommended in [22], which involves the comparison between $T_{\beta}$ and the harmonic mean temperature $\left(T_{h m}\right)$ :

$$
T_{h m}=\frac{n}{\sum_{i=1}^{n}(1 / T)}
$$

where $n$ is the number of experimental isotherms.

The EECT postulate is valid on the condition that $T_{\beta} \neq T_{h m}$. Depending on the numerical correlation between the two parameters, the process may be governed either by enthalpy $\left(T_{\beta}\right.$ $\left.>T_{h m}\right)$ or by entropy $\left(T_{\beta}<T_{h m}\right)[23]$.

According to [24], the parameter $\left(\Delta G_{\beta}\right)$ has limited impact on enthalpy variation and can be excluded from the model; thus, the following equation is obtained:

$$
-\ln \left(a_{w}\right)=\frac{Q_{s t, n}}{R}\left(\frac{1}{T}-\frac{1}{T_{\beta}}\right)
$$

The following equation proposed in $[24,25]$ discloses the application of the EECT in the assessment of the relationship between the temperature and the adsorption capacity:

$$
\left(\frac{1}{T}-\frac{1}{T_{\beta}}\right)^{-1} \ln \left(a_{w}\right)=K f(M)
$$

where $f(M)$ is an empirical function of $M_{e q}$.

Therefore, the experimental sorption data can be presented on the graph with coordinates $\ln \left(\left(\frac{1}{T}-\frac{1}{T_{\beta}}\right)^{-1} \ln \left(a_{w}\right)\right)$ and $M_{e q}$, respectively. In this context, [24] and [26] recommend an adequate exponential function for the water equilibrium in foods that takes into consideration the influence of temperature, in the following form:

$$
\left(\frac{1}{T}-\frac{1}{T_{\beta}}\right)^{-1} \ln \left(a_{w}\right)=K_{1} K_{2}^{M}
$$

Then

$$
\ln \left|\left(\frac{1}{T}-\frac{1}{T_{\beta}}\right)^{-1} \ln \left(a_{w}\right)\right|=\ln \left(K_{1}\right)+M \ln \left(K_{2}\right)
$$

After plotting $\ln \left(\left(\frac{1}{T}-\frac{1}{T_{\beta}}\right)^{-1} \ln \left(a_{w}\right)\right)$ versus $M, K_{l}$ and $K_{2}$ are defined as coefficients of the linear equation.

\section{Results and discussion}

\subsection{Isosteric heat of desorption and differential entropy}

The precise characterization of the scale of the heat of sorption, i.e. the energy of the bonds between water molecules and the solid skeleton, plays a decisive role in equipment design and in mode selection for the drying of a given product [25]. In order to eliminate water from a moist material by heat drying, water has to evaporate and vapors must migrate outside the product. The phase liquid-to-vapor conversion involves certain energy consumption. The isothermal evaporation of bound water requires an additional amount of energy, which is to 
be used for the disruption of water-material bonds; namely, that represents the heat of sorption.

The Chung-Pfost model (eq. 1), previously defined as the most adequate for the description of the obtained desorption isotherms of tobacco seeds, was applied for the determination of the isosteric heat of desorption and the entropy change in the desorption process. The results are shown in Fig. 1; each straight line approximating the calculated data sets the pattern of the change in the amount of heat necessary for water elimination at a given moisture content. From the slope of each line $\left(\frac{Q_{s t, n}}{R}\right)$, determined by the least-square method, the respective values of the isosteric heat of desorption were calculated.

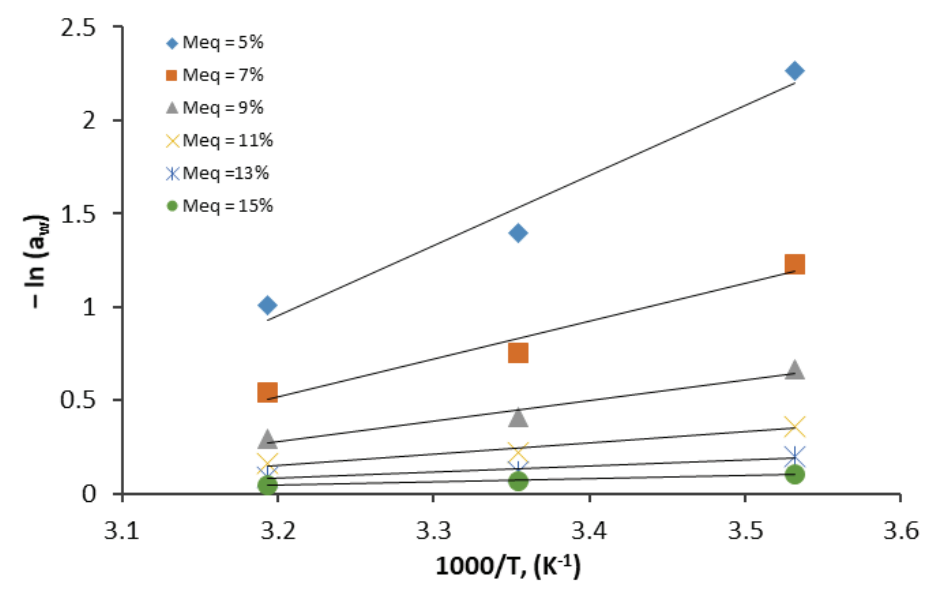

Fig. 1. Desorption isosterics of tobacco seeds.

The correlation between the two parameters for tobacco seeds, derived from the ClausiusClapeyron equation, $Q_{s t, n}$ and $M_{e q}$, is given in Fig. 2. As seen in this figure, $Q_{s t, n}$ decreased significantly with the elevation of $M_{e q}$ values, from 31.09 to $1.46 \mathrm{~kJ} \mathrm{~mol}^{-1}$ in the specified variation range of $M_{e q}$ between $5 \%$ and $15 \%$ d.b.

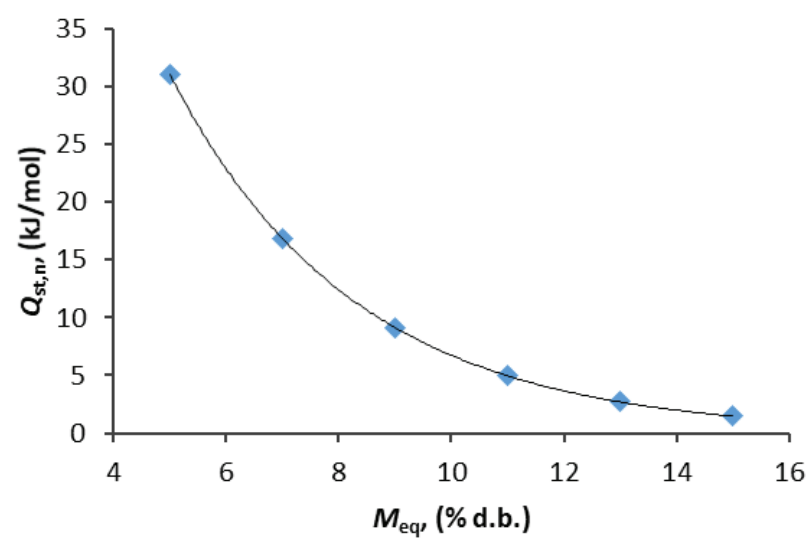

Fig. 2. Isosteric heat of desorption $Q_{\mathrm{st}, \mathrm{n}}$ of tobacco seeds

The observation of high $Q_{s t, n}$ values at low $M_{e q}$ levels is associated with the availability of active locations on object's surface (tobacco seeds), which are the attractive spots for the formation of water monomolecular layers $[21,27]$. These layers require greater amounts of 
energy in order to remove water molecules from the material [27]. With the advance of moisture incorporation within the solid body (increased $M_{e q}$ of tobacco seeds) the number of accessible water-bonding sites decreases, subsequently lower values of $Q_{s t, n}$ are being established [28]. These observations are fully supported by previous findings for other solid plant fractions, such as lime seeds [29] and coffee beans [19].

The Tsami equation as announced in [21] was applied to examine the impact of the change in the $M_{e q}$ content on $Q_{s t, n}$ in the drying of tobacco seeds, in the following form:

$$
Q_{\text {st }, \text { pred }}=q_{0} \exp \left(-\frac{M_{e q}}{M_{0}}\right)=143.43 \exp \left(-\frac{M_{e q}}{0.033}\right)
$$

In this equation, the $q_{o}$ and $M_{o}$ values for the processed desorption data were 143.43 $\mathrm{kJ} . \mathrm{mol}^{-1}$ and $3.3 \%$ d.b., respectively, with $R^{2}$ equal to 1.0 .

The Tsami model was also used to assess the $Q_{s t, n} / M_{e q}$ interrelation for tobacco seeds, considering analogous observations for other plant matrices, for example coffee [19] and red algae [30].

The respective levels of $\Delta S$ corresponding to each of the regarded $M_{e q}$ variations were determined by relating the equilibrium data with equation (6). Fig. 3 displays the functional dependency between $\Delta S$ and $M_{e q}$ resulting from these calculations.

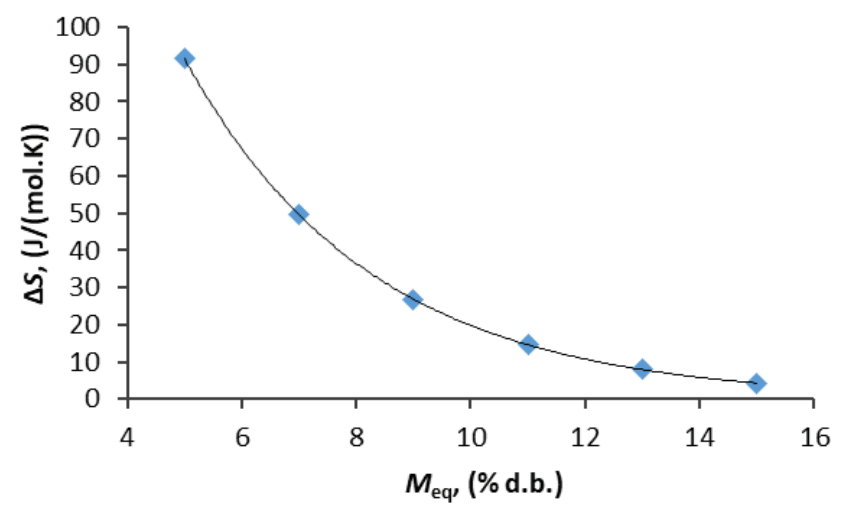

Fig. 3. Differential entropy $(\Delta S)$ of tobacco seeds

The results suggested a strong inverse relationship between the two characteristics of the water transfer process in tobacco seeds, $\Delta S$ and $M_{e q}$; the relationship profile was similar to the observations regarding $Q_{s t, n}$ response to $M_{e q}$ variation. The values of $\Delta S$ ranged from 4.29 to $91.53 \mathrm{~J} . \mathrm{mol}^{-1} \cdot \mathrm{K}^{-1}$ at $M_{e q}$ levels decreasing from 15 to $5 \%$ d.b. Our findings complied well with the statement that the differential entropy is reduced when molecular movements are more restricted, i.e. when the material is with a higher water content [27].

Comparable data are found in the studies by [4] for the desorption entropy of garlic, by [31] for melon seed and cassava, and by [32] for sesame seeds.

The results about the variation of $\Delta S$ by $M_{e q}$ for tobacco seeds were adequately expressed by the following exponential equation:

$$
\Delta S=422.76 \exp \left(-\frac{M_{e q}}{0.033}\right)
$$




\subsection{Enthalpy-entropy compensation}

A marked straight line related $Q_{s t, n}$ to $\Delta S$ for tobacco seeds, within the integrated temperature range (Fig. 4). The presence of pronounced and proportionate interrelation between the two thermodynamic indicators provides evidence in support of the EECT supposition, as described above [23].

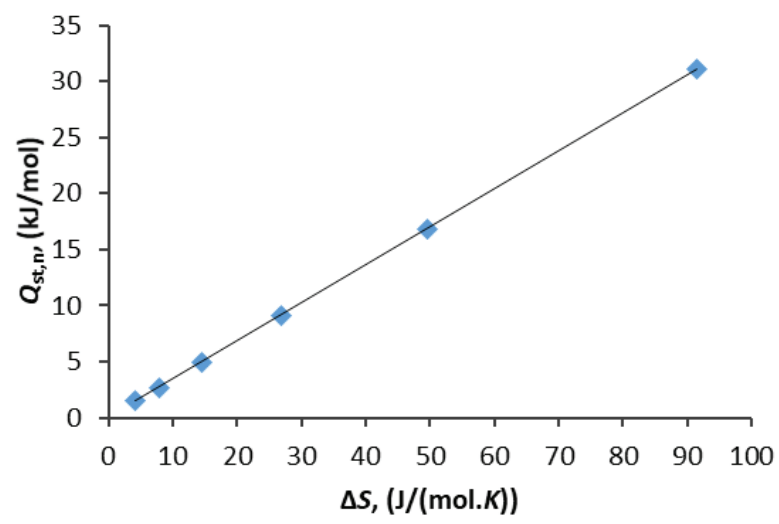

Fig. 4. Enthalpy-entropy relationship for water desorption in tobacco seeds

Further, the isokinetic temperature $\left(T_{\beta}\right)$ and the free energy $\left(\Delta G_{\beta}\right)$ were defined (Eq. (8)), and the characteristic parameters of the enthalpy-entropy relationship for tobacco seeds were:

$$
Q_{s t, n}=0.3396 \Delta S+0.0033
$$

The positive sign of the $\Delta G_{\beta}$ value is indicative of an energy-absorbing non-spontaneous reaction, which obliges energy provision from the surrounding environment into the material [3]. The value of $\Delta G_{\beta}$ for the studied tobacco seeds, averaged over the entire water content domain, was found to be positive but low $\left(3.3 \mathrm{~J} . \mathrm{mol}^{-1}\right)$, thus indicating a non-spontaneous desorption process.

The isokinetic temperature value $\left(T_{\beta}\right)$ was $339.6 \mathrm{~K}$ and the harmonic temperature $\left(T_{h m}\right)$ was found to be $297.5 \mathrm{~K}$. It was observed that $T_{\beta} \neq T_{h m}$ and this difference corroborates the enthalpy-entropy compensation theory. In particular, our results showed that $T_{\beta}>T_{h m}$, therefore the desorption process of tobacco seeds is an enthalpy-driven mechanism [23]; this suggests that tobacco seeds are a stable solid matrix and are not susceptible for structural alterations accompanying the moisture removal within the $10^{\circ} \mathrm{C} \div 40^{\circ} \mathrm{C}$ temperature zone.

The next step in the study was the application of the EECT for demonstrating the temperature influence on the sorption of tobacco seeds using equations (12) and (13). Fig. 5 shows the graph between the temperature-related factor $\ln \left(\left(\frac{1}{T}-\frac{1}{T_{\beta}}\right)^{-1} \ln \left(a_{w}\right)\right)$ and the $M_{e q}$ of tobacco seeds; as seen, the approximation was that of a straight line. The constants in the equation, $K_{I}$ and $K_{2}$, took values of $17306.3 \mathrm{~K}$ and 0.74 , respectively (determined by linear regression). Our results were consistent with previous findings [2], which determined $K_{l}$ and $K_{2}$ values for sucuk (Turkish dry-fermented sausage) as equal to $5226 \mathrm{~K}$ and 0.902 , respectively. 


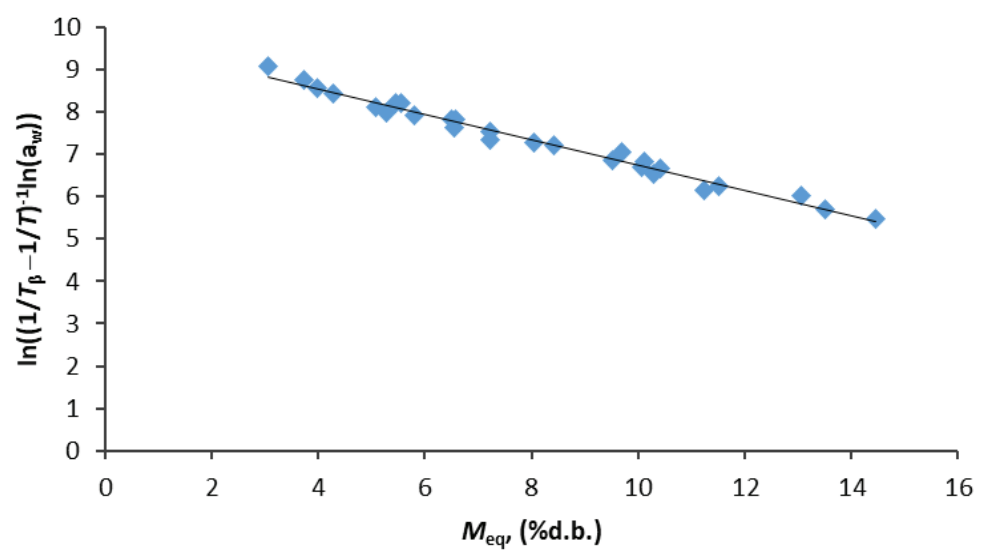

Fig. 5. Equilibrium moisture content $\left(M_{e q}\right)$ plotted according to equation (13)

Therefore, the EECT (the isokinetic theory) could be effectively spread over the water desorption by tobacco seeds, identified in this study as an enthalpy-controlled process.

\section{Conclusions}

The net isosteric heat of desorption and the differential entropy of tobacco seeds (variety "Kroumovgrad 90", Oriental type) were defined based on experimental desorption data, obtained at $10^{\circ} \mathrm{C}, 25^{\circ} \mathrm{C}$ and $40^{\circ} \mathrm{C}$, and water activity level from 0.113 to 0.823 . Both thermodynamic indices showed inverse, exponential in form, relationship with the equilibrium moisture content. The value of Gibbs free energy had a positive sign and the isokinetic temperature value $(339.6 \mathrm{~K})$ exceeded that of the harmonic temperature $(297.5 \mathrm{~K})$, thus revealing that moisture desorption from tobacco seeds was an endergonic and enthalpycontrolled process. Therefore, the EECT fitted adequately the water desorption characteristics of tobacco seeds. These findings contribute to the deeper insight into the process of moisture desorption of tobacco seeds.

This study did not receive any specific funding.

\section{References}

1. A.L. Gabas, V.R.N. Telis, P.J.A. Sobral, J. Telis-Romero, J. Food Eng. 82, 246-252 (2007)

2. B. Polatoglu, A. Vildan Bese, M. Kaya, N. Aktas, Food Bioprod. Process. 89, 449-456 (2011)

3. L. Hassini, E. Bettaieb, H. Desmorieux, S.S. Torres, A. Touil, Ind. Crops Prod. 67, 457465 (2015)

4. P.S. Madamba, R.H. Driscoll, K.A. Buckle, J. Food Eng. 28, 109-119 (1996)

5. A.L. Gabas, F.C. Menegalli, J. Telis-Romero, J. Food Sci. 65, 680-684 (2000)

6. C.I. Beristain, H.S Garcia, E. Azuara, J. Food Eng. 30, 405-415 (1996)

7. P.C. Moyano, R.N. Zuniga, J. Food Eng. 63, 57-62 (2004)

8. O.O. Fasina, J. Food Eng. 75, 149-155 (2006)

9. M. Banožić, J. Babić, S. Jokić, Ind. Crops Prod. 144, 112009 (2020) 
10. Y. Yonchev, Y. Dyulgerski, Bulg. J. Crop Sci. 53, 30-35 (2016)

11. Y. Dyulgerski, Bulg. J. Agric. Sci. 26(1), 128-131 (2020)

12. M. Zlatanov, M. Angelova, G. Antova, Bulg. J. Agric. Sci. 13, 539-544 (2007)

13. S. Grisan, R. Polizzotto, P. Raiola, S. Cristiani, F. Ventura, F. di Licia, M. Zuin, S. Tommasini, R. Morbidelli, F. Damiani, F. Pupilli, M. Bellucci, Agron. Sustain. Dev. 36, 54-55 (2016)

14. V. Popova, Z. Petkova, T. Ivanova, M. Stoyanova, L. Lazarov, A. Stoyanova, T. Hristeva, M. Docheva, V. Nikolova, N. Nikolov, V.D. Zheljazkov, Ind. Crops Prod. 117, 375-381 (2018)

15. American Society of Agricultural Engineers, Standard D245.5. (ASAE, St. Joseph, Michigan, 1997)

16. Ministry of Agriculture, Food and Forestry of the Republic of Bulgaria. Ordinance No 29 of July 22, 2004 on the production and distribution of seeds from tobacco, State Gazette of the Republic of Bulgaria, 60 (2004)

17. S. Simal, A. Femenia, A. Castell-Palou, C. Rossello, J. Food Eng. 80, 1293-1301 (2007)

18. J.V. Garcia-Perez, J.A. Carcel, G. Clemente, A. Mulet, LWT - Food Sci. Technol. 41, 18-25 (2008)

19. P.C. Correa, A.L.D. Goneli, P.C.A. Junior, G.H.H. De Oliveira, D.S.M. Valente, Int. J. Food Sci. Technol. 45, 2016-2022 (2010)

20. W.A.M. McMinn, A.H. Al-Muhtaseb, T.R.A. Magee, Food Res. Int. 38, 505-510 (2005)

21. E. Tsami, J. Food Eng. 14, 327-335 (1991)

22. R.R. Krug, W.G. Hunter, R.A. Grieger, J. Phys. Chem. 80, 2335-2341 (1976)

23. J.E. Lefer, E. Grunwald, Rates and Equilibria of Organic Reactions (Wiley, New York, 1963)

24. R.J. Aguerre, C.Suarez, P.E. Viollaz, J. Food Sci. 51, 1547-1549 (1986)

25. N. Arslan, H. Toğrul, J. Food Eng. 69(2), 133-145 (2005)

26. S. Ouertani, S. Azzous, L. Hassini, A. Koubba, A. Belghith, Ind. Crops Prod. 56, 200210 (2014)

27. V.S. Eim, C. Rosselo, A. Femenia, S. Simal, Int. J. Food Eng. 7(3), 1-14 (2011)

28. A. Jayendra Kumar, R.R.B. Singh, G.R. Patil, A.A. Patel, LWT - Food Sci. Technol. 38, 303-310 (2005)

29. H. Váquiro, S. Simal, G. Carvalho, J. Telis - Romero, EuroDrying '2011 (Palma, Balearic Island, Spain, 26-28 October 2011)

30. R.A. Lemus, M. Pérez, A. Andrés, T. Roco, C.M. Tello, A. Vega, LWT - Food Sci. Technol. 41(9), 1592-1599 (2008)

31. N.A. Aviara, O.O. Ajibola, J. Food Eng. 55, 107-113 (2002)

32. S. Kaya, T. Kahyaoglu, J. Food Eng. 76, 139-147 (2006) 